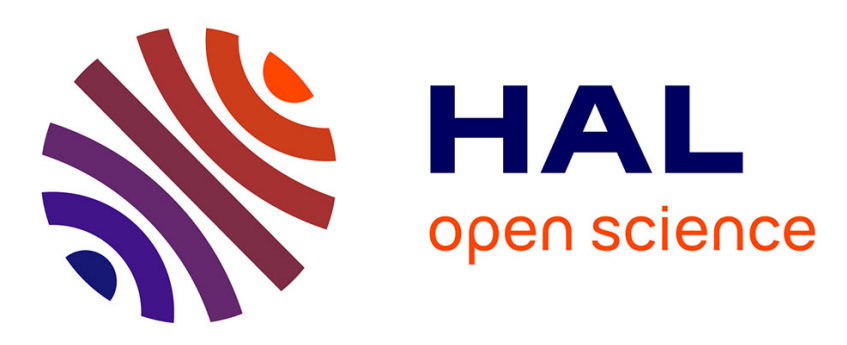

\title{
Magnetic tunnel junctions with a zinc oxide - cobalt oxide composite tunnel barrier
}

Laurent Le Brizoual, Patrick Alnot, Michel Hehn, François Montaigne, M. Alnot, A. Schuhl, Etienne Snoeck

\section{- To cite this version:}

Laurent Le Brizoual, Patrick Alnot, Michel Hehn, François Montaigne, M. Alnot, et al.. Magnetic tunnel junctions with a zinc oxide - cobalt oxide composite tunnel barrier. Applied Physics Letters, 2005, 86 (11), pp.112505-1 - 112505-3. 10.1063/1.1882762 . hal-00080481

\section{HAL Id: hal-00080481 https://hal.science/hal-00080481}

Submitted on 2 Mar 2018

HAL is a multi-disciplinary open access archive for the deposit and dissemination of scientific research documents, whether they are published or not. The documents may come from teaching and research institutions in France or abroad, or from public or private research centers.
L'archive ouverte pluridisciplinaire HAL, est destinée au dépôt et à la diffusion de documents scientifiques de niveau recherche, publiés ou non, émanant des établissements d'enseignement et de recherche français ou étrangers, des laboratoires publics ou privés. 


\section{Magnetic tunnel junctions with a zinc oxide-cobalt oxide composite tunnel barrier}

L. Le Brizoual, P. Alnot, M. Hehn, F. Montaigne, M. Alnot, A. Schuhl, and E. Snoeck

Citation: Appl. Phys. Lett. 86, 112505 (2005); doi: 10.1063/1.1882762

View online: https://doi.org/10.1063/1.1882762

View Table of Contents: http://aip.scitation.org/toc/apl/86/11

Published by the American Institute of Physics

\section{Articles you may be interested in}

Tunnel magnetoresistance of $604 \%$ at $300 \mathrm{~K}$ by suppression of Ta diffusion in $\mathrm{CoFe} B / \mathrm{MgO} / \mathrm{CoFe} B$ pseudospin-valves annealed at high temperature

Applied Physics Letters 93, 082508 (2008); 10.1063/1.2976435

Giant tunneling magnetoresistance in fully epitaxial body-centered-cubic $\mathrm{Co} / \mathrm{MgO} / \mathrm{Fe}$ magnetic tunnel junctions Applied Physics Letters 87, 222508 (2005); 10.1063/1.2138355

Enhanced tunnel magnetoresistance in fully epitaxial $\mathrm{ZnO}$ :Co-based magnetic tunnel junctions with Mg-doped ZnO barrier

Applied Physics Letters 100, 132406 (2012); 10.1063/1.3698151

Giant tunneling magnetoresistance up to $410 \%$ at room temperature in fully epitaxial $\mathrm{Co} / \mathrm{MgO} / \mathrm{Co}$ magnetic tunnel junctions with bcc $\mathrm{Co}(001)$ electrodes

Applied Physics Letters 89, 042505 (2006); 10.1063/1.2236268

Tunnel magnetoresistance in magnetic tunnel junctions with a ZnS barrier

Applied Physics Letters 78, 3487 (2001); 10.1063/1.1372206

High temperature annealing stability of magnetic properties in MgO-based perpendicular magnetic tunnel junction stacks with CoFeB polarizing layer

Journal of Applied Physics 109, 07 C709 (2011); 10.1063/1.3549605

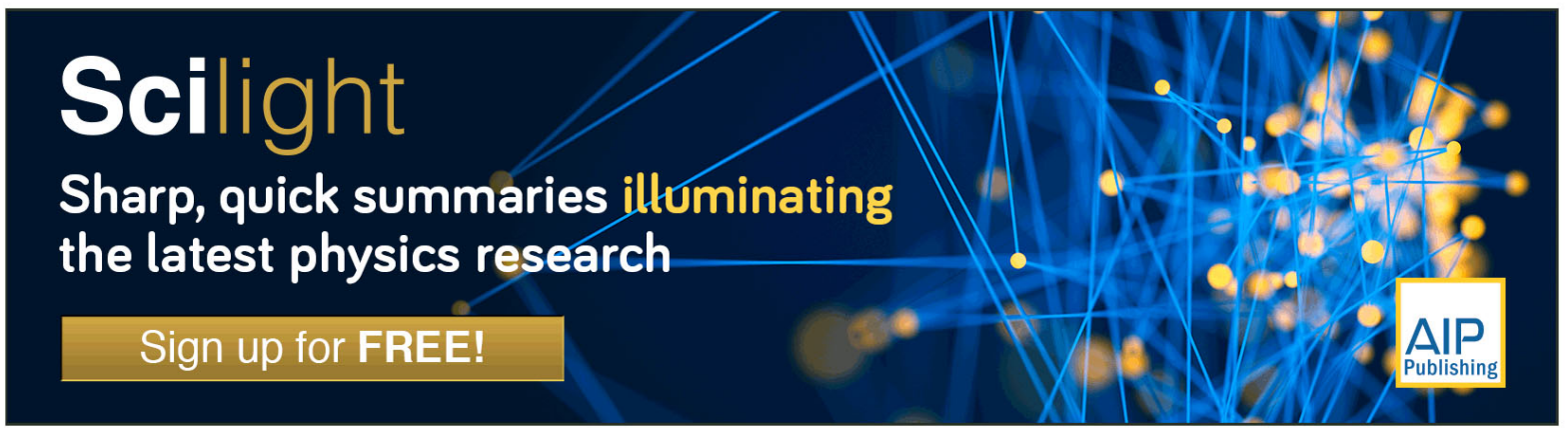




\title{
Magnetic tunnel junctions with a zinc oxide-cobalt oxide composite tunnel barrier
}

\author{
L. Le Brizoual and P. Alnot \\ Laboratoire de Physique des Milieux Ionisés et Applications, UMR CNRS 7040, BP 239, 54506 Vandoeuvre \\ lès Nancy Cedex, France \\ M. Hehn, ${ }^{a)}$ F. Montaigne, M. Alnot, and A. Schuhl \\ Laboratoire de Physique des Matériaux, UMR CNRS 7556, B.P. 239, 54506 Vandoeuvre \\ lès Nancy Cedex, France \\ E. Snoeck \\ CEMES-CNRS-Groupe NanoMatériaux, 29 rue Jeanne Marvig, B.P. 94347, F-31055 Toulouse \\ Cedex, France
}

(Received 22 September 2004; accepted 21 January 2005; published online 8 March 2005)

\begin{abstract}
Composite $\mathrm{CoO}-\mathrm{ZnO}$ tunnel junctions showing nonlinear and asymmetric current-voltage characteristics with significant magnetoresistance ratios (up to $8 \%$ at $77 \mathrm{~K}$ ) have been prepared by using reactive sputtering from a zinc target. Electron transmission microscopy demonstrates the formation of a zinc oxide-cobalt oxide bilayer. Observed asymmetries, which are directly linked to the difference in zinc oxide and cobalt oxide barrier heights are in good agreement with calculations done within the framework of a parabolic bands model, using thicknesses extracted from transmission electron microscopy (TEM) images and barrier heights found in literature.
\end{abstract}

(C) 2005 American Institute of Physics. [DOI: 10.1063/1.1882762]

Since the discovery of spin dependent Tunneling (SDT) across a Ge barrier by Jullière, ${ }^{1}$ SDT has been shown to occur using others tunnel barrier materials. Therefore, several barrier growth methods have been developed and optimized. As far as amorphous barriers are concerned, the most used techniques are based on the post oxidation of a previous deposited metallic layer. ${ }^{2-6}$ Indeed, several attempts have been made by sputtering directly the barrier materials from an oxide target, ${ }^{7,8}$ or by performing a reactive sputtering from a metallic target. ${ }^{9,10}$ However, since oxygen has to be added to the plasma to reach the film stoichiometry, it leads to an oxidation of the bottom electrode. Nevertheless, one can take advantage of this in order to obtain composite tunnel junctions. As soon as such junctions are expected to show highly nonsymmetric electrical characteristics, ${ }^{11}$ it would have an important technological impact, for example, for the magnetic random access memory (MRAM) production. ${ }^{12}$

In this letter, we present our study on $\mathrm{CoO}-\mathrm{ZnO}$ composite tunnel barriers. Those double barriers are made of a $\mathrm{CoO}-\mathrm{ZnO}$ bilayer where the $\mathrm{ZnO}$ insulating layer is grown on the top of a $\mathrm{CoO}$ layer covering the Co bottom electrode. Zinc oxide layers were prepared by reactive sputtering from a zinc target. $\mathrm{ZnO}$ thin films are mainly applied in various fields such as surface acoustic waves, ${ }^{13}$ optoelectronics devices $^{14}$ and transparent conducting coating ${ }^{15}$ but no attempt was made up until now to use them as tunnel barriers. However, this material could be used with $\mathrm{Zn}_{1-x} \mathrm{Co}_{x} \mathrm{O}^{16}$ predicted to be a magnetic semiconductor at room temperature in $\mathrm{Zn}_{1-x} \mathrm{Co}_{x} \mathrm{O}-\mathrm{ZnO}-\mathrm{Zn}_{1-x} \mathrm{Co}_{x} \mathrm{O}$ multilayers. In this letter, we report a tunnel magnetoresistance ratio of $8 \%$ at $77 \mathrm{~K}$ with nonlinear and asymmetric current-voltage characteristic using a $\mathrm{ZnO}-\mathrm{CoO}$ double barrier. It appears that the control of the bottom $\mathrm{CoO}$ layer thickness is the key to optimize the

${ }^{a)}$ Electronic mail: hehn@lpm.u-nancy.fr magnetic-field dependent current-voltage characteristics of these potential rectifying diodes.

Junctions are deposited onto float-glass substrates by sputtering cobalt and zinc targets. The samples studied are nominally composed of Glass//Ta $(10 \mathrm{~nm}) / \mathrm{Co}(10 \mathrm{~nm}) / /$ $\mathrm{ZnO}(3 \mathrm{~nm}) / / \mathrm{Co}^{*}(20 \mathrm{~nm})$. After sputter-etching of the glass substrate, a $\mathrm{Ta}(10 \mathrm{~nm}) / \mathrm{Co}(10 \mathrm{~nm})$ bilayer is grown at room temperature at an operating pressure of $5 \cdot 10^{-3}$ mbar. In previous studies, ${ }^{17}$ we showed that those deposition conditions result in a smooth surface with peak to peak roughness less than $1 \mathrm{~nm}$. Then, the sample is brought back to the air and transferred in a different apparatus in which the $\mathrm{ZnO}$ thin films are grown by de reactive sputtering of a zinc target. The sample is heated to $200{ }^{\circ} \mathrm{C}$ and then an argon-oxygen gas mixture is introduced with a total pressure of $2 \cdot 10^{-3} \mathrm{mbar}$ and an oxygen percentage of $70 \%$. A $120 \mathrm{~W} \mathrm{dc}$ power is applied on a planar magnetron for $\mathrm{ZnO}$ deposition at $0.8 \AA / \mathrm{s}$. These optimized deposition conditions lead to good piezoelectric quality and stoichiometric $\mathrm{ZnO}$ thin films. ${ }^{18}$ Finally, the sample is again brought back to the air and transferred for deposition of the top Co layer referred to as $\mathrm{Co}^{*}$ is deposited at $1.5 \cdot 10^{-2}$ mbar. The films deposited at this high pressure have an increased coercivity field of about 200 Oe at room temperature compared to 65 Oe for the bottom electrode. The same growth procedure (with the same "bring back to the air") gives magnetic tunnel junctions with a 15\% tunnel magnetoresistance (TMR) for a $2.5 \mathrm{~nm}$ thick alumina barrier.

Transmission electron microscopy (TEM) experiments on cross sectional specimen were carried out on a Philips CM30 microscope. Low magnification TEM images indicate that even if the interfaces are very rough, the $\mathrm{ZnO}$ barrier is continuous over distances as long as at least $0.5 \mu \mathrm{m}$ as illustrated in Fig. 1(a). In the high-resolution TEM (HRTEM) experiments, Fig. 1(b), the $\mathrm{ZnO}$ barrier is polycrystalline with a thickness of about $3 \mathrm{~nm}$ and a grain size no larger than 

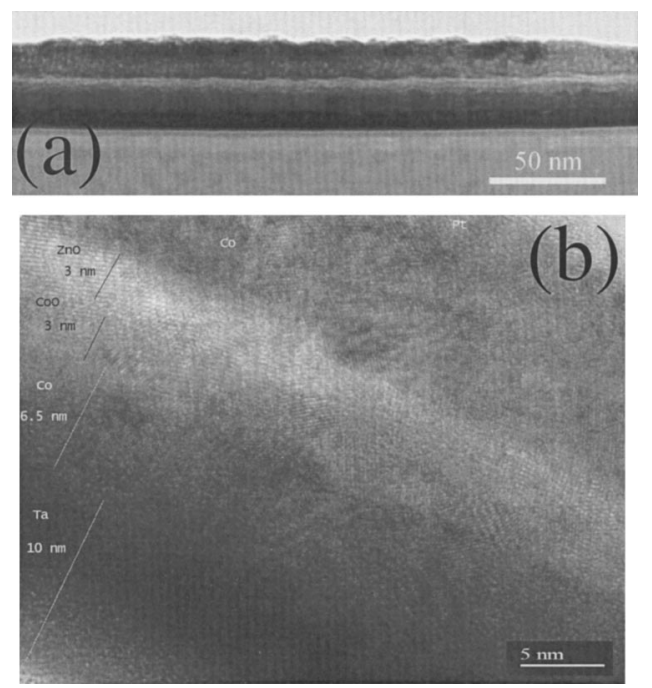

FIG. 1. (a) Low magnification TEM micrograph evidencing the continuity of the $\mathrm{ZnO}$ barrier with a regular roughness; (b) HRTEM image evidencing the appearance of a $3 \mathrm{~nm}$ thick $\mathrm{CoO}$ layer located between the $\mathrm{ZnO}$ barrier and the bottom Co electrode.

$8 \mathrm{~nm}$. The lattice parameters, evaluated to 2.6 and $2.77 \AA$, correspond to the hexagonal $\mathrm{ZnO}$ phase $(2.603$ and $2.814 \AA$ in bulk) and exclude the other $\mathrm{ZnO}_{x}$ phases. Moreover, a TEM contrast different to the one observed in the Co layers is observed in a $3 \mathrm{~nm}$ thick layer running between the $\mathrm{ZnO}$ oxide layer and the Co bottom electrode. The lattice distance evaluated to $2.6 \AA$ in that layer indicates that it corresponds to a $\mathrm{CoO}$ oxide film (2.62 $\AA$ in bulk) and excludes the other $\mathrm{Co}_{x} \mathrm{O}_{y}$ phases. This TEM analysis shows clearly that using oxygen reactive sputtering to make magnetic tunnel junctions leads to the oxidation of the bottom magnetic electrode. Then hybrid composite $\mathrm{CoO}-\mathrm{ZnO}$ tunnel barriers are stabilized. However, we cannot exclude that a precursory $\mathrm{CoO}$ layer forms during the time spent outside the sputtering plan. Then, experimentally, no correlation could be found between the time spend in the air between the deposition of the Ta-Co and the $\mathrm{ZnO}$ barrier growth and the transport characteristics. This is in accordance to studies of the oxidation process of thin Co layers. ${ }^{19}$ As soon as a Co layer with thickness above $5 \mathrm{~nm}$ is exposed to the air, a thin passivation $\mathrm{CoO}$ layer forms. Its thickness does not evolve with time. In Ref. 19, the thickness of the passivation $\mathrm{CoO}$ layer has been found to be $2.5 \mathrm{~nm}$.

In order to perform the magneto-electrical characterization, junctions are defined in a cross-strip geometry through metallic contact masks. The path width is $200 \mu \mathrm{m}$ and each sample contains 14 tunnel junctions $200 \mu \mathrm{m} \times 200 \mu \mathrm{m}$ in size. ${ }^{17}$ The resistance is measured with a standard two-probe dc technique, the positive voltage being applied on the top electrode. The average yield is about $50 \%$ of junctions with resistances exceeding the lead resistance by at least a factor of ten. At room temperature, the $I(V)$ curves are nonlinear and symmetric and no evidence of TMR could be found even if electrodes have been shown to be magnetically decoupled using Kerr magnetometry. Nevertheless, $I(V)$ were fitted using the Brinkman formula ${ }^{20}$ and a barrier height of $0.91 \mathrm{eV}$ and a barrier thickness of $2.1 \mathrm{~nm}$ could be extracted. At 77 $\mathrm{K}$, the $I(\mathrm{~V})$ curves are nonlinear and asymmetric [Fig. 2(a)] and the junction resistance varies between 6 and $25 \mathrm{k} \Omega$. The voltage dependent current asymmetry, defined as
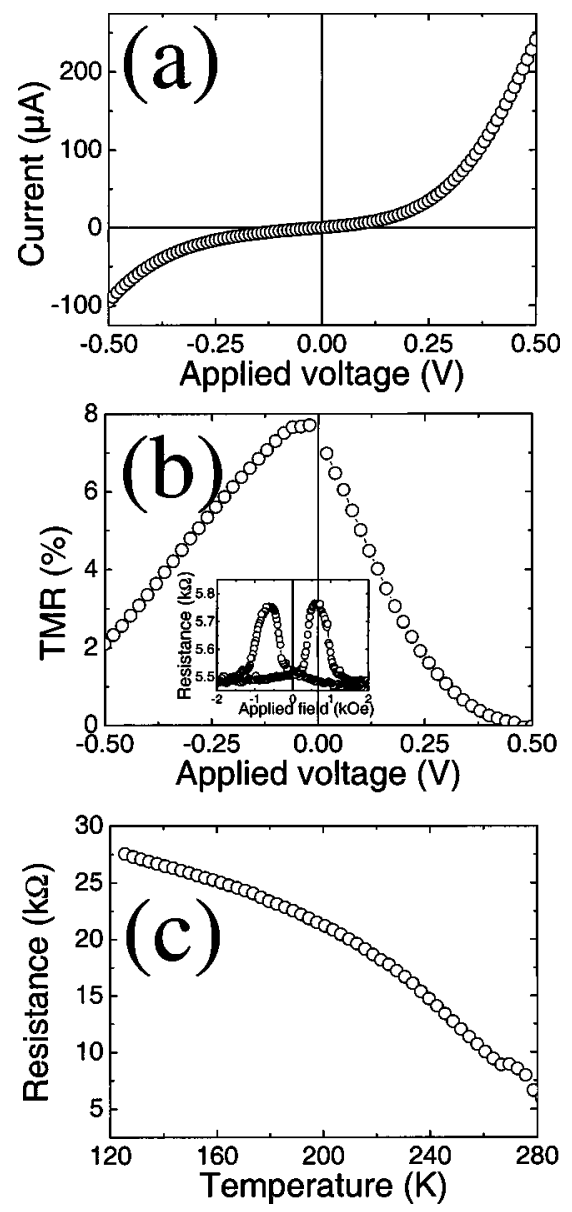

FIG. 2. (a) Current versus voltage and (b) magneto-resistance vs voltage at 77 K (inset: Resistance vs field); (c) resistance vs temperature measured on a Glass- $\mathrm{Ta}(10 \mathrm{~nm}) / \mathrm{Co}(10 \mathrm{~nm}) / \mathrm{ZnO}(3 \mathrm{~nm}) / \mathrm{Co}(20 \mathrm{~nm})$ tunnel junction.

$\alpha(V)=I(+V) / I(-V)$, increases with applied voltage when the bottom electrode is positively biased and reaches $2-5$ at 0.5 V. Furthermore, a TMR signal with values from $4 \%$ up to $8 \%$ could be observed [Fig. 2(b)]. The TMR versus applied voltage characteristic, $\operatorname{TMR}(V)$, is asymmetric and, particularly interesting, the TMR maximum is shifted to the negative bias. This asymmetry can originate from a different $\mathrm{Co}-\mathrm{ZnO}$ and $\mathrm{ZnO}-\mathrm{Co}^{*}$ interface smoothness but also from a different $\mathrm{Co}-\mathrm{ZnO}$ and $\mathrm{ZnO}-\mathrm{Co}^{*}$ interface barrier height. Then, the barrier height at $\mathrm{Co}-\mathrm{ZnO}$ interface is less than the one at the $\mathrm{ZnO}-\mathrm{Co}^{*}$ interface. Finally, the temperature-dependent resistivity, $R(T)$, has been measured on those junctions. As shown by Akerman et al. ${ }^{21}$ this is the most reliable tunneling criteria. This last characteristic is reported in Fig. 2(c) for an applied voltage of $10 \mathrm{mV}$. No divergence of resistance could be observed as temperature is decreased. Then, elastic electron tunneling remains the principal transport mechanism with respect to electron hopping inside the barrier. ${ }^{22}$ However, the resistance varies by a factor of 5-10 and this large variation is beyond the one predicted from the smearing of the Fermi function as shown, for example, by Stratton. ${ }^{23}$

We thus have tried to understand these features using a simple model of the tunnel magnetoresistance. A parabolic bands approximation allows to simply solve the Schrödinger equation for an arbitrary potential and to take into account the composite nature of the barrier. The model we have used is described in Ref. 11 and is basically an extension of the approach proposed by Slonczewski ${ }^{24}$ including an exact nu- 

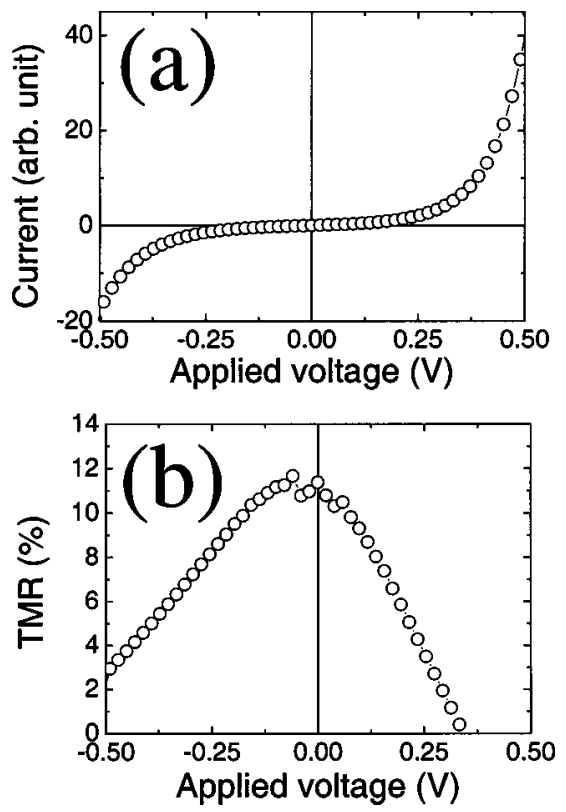

FIG. 3. (a) Current vs voltage and (b) magneto-resistance vs voltage computed in the free electron model on a $\mathrm{CoO}-\mathrm{ZnO}$ composite tunnel barrier using thicknesses extracted from TEM images and barrier heights found in literature.

merical resolution of the Schrödinger equation and a complete integration of the tunneling coefficient over all the states. The parameters used into the model are the thicknesses of the $\mathrm{CoO}$ and $\mathrm{ZnO}$ layers, equal to $3 \mathrm{~nm}$ from the TEM pictures, and the barrier heights found in literature, equal to $0.6 \mathrm{eV}$ for $\mathrm{CoO}^{25}$ and $1 \mathrm{eV}$ for $\mathrm{ZnO}^{26}$ Indeed, those parameters could not be extracted from fitting the $I(V)$ curves as it is done commonly. To model the electrode bands, we used the parameters proposed by Davis et al. ${ }^{27}$ It appears clearly in Fig. 3 that all features described in Fig. 2 can be fairly reproduced and especially $I(V)$ and TMR $(V)$ asymmetries. Changing slightly barrier heights and/or thicknesses does not modify drastically the shape of those curves but asymmetries are linked to the difference in barrier heights of the $\mathrm{CoO}$ and $\mathrm{ZnO}$ tunnel barriers. The low temperature features are thus well explained considering the composite nature of the barrier.

On the other hand, the lack of TMR and the symmetric $I(V)$ curve at room temperature contrast with this picture. The important temperature dependance of the resistance, a factor of 5 between 300 and $77 \mathrm{~K}$, indicates the existence of thermally activated modes of conduction. The effective parameters deduced from the room temperature $I(V)$ curves, fitted effective barrier height of $0.91 \mathrm{eV}$ and a barrier thickness of $2.1 \mathrm{~nm}$, could be interpreted as the one of a single $\mathrm{ZnO}$ barrier. This would imply that the thermally activated transport is mostly related to $\mathrm{CoO}$ which loses its insulating character at room temperature. This behavior has already been observed by Platt $e t a .^{25}$ The suppression of TMR at room temperature is then explained by the progressive transition from a ferromagnetic Co bottom electrode with a $\mathrm{CoO}-\mathrm{ZnO}$ barrier to a non polarized $\mathrm{CoO}$ electrode with a
$\mathrm{ZnO}$ barrier. Indeed, at room temperature, $\mathrm{CoO}$ is either antiferromagnetic or paramagnetic.

The good agreement between our low temperature experimental data and the free electron model make us confident in the prediction of this theoretical approach, which predicts we can achieve much higher asymmetry ratio by decreasing the $\mathrm{CoO}$ layer thickness. Indeed, the control of the bottom $\mathrm{CoO}$ layer thickness is the key to optimize the magnetic field dependent current-voltage characteristics of these rectifying diodes. The oxidation of the bottom electrode is caused of course by the atmosphere when the sample is transferred (and the metallic mask changed) but also and mainly by the oxygen reactive atmosphere during the $\mathrm{ZnO}$ deposition.

${ }^{1}$ M. Jullière, Phys. Lett. 54A, 225 (1975).

${ }^{2}$ J. Zhang, R. M. White, J. Appl. Phys. 83, 6512 (1998); J. Nassar, M. Hehn, A. Vaurès, F. Petroff, and A. Fert, Appl. Phys. Lett. 73, 698 (1998).

${ }^{3}$ M. Tsunoda, K. Nishikawa, S. Ogata, and M. Takahashi, Appl. Phys. Lett. 80, 3135 (2002).

${ }^{4}$ W. Zhu, C. J. Hirschmugl, A. D. Laine, B. Sinkovic, and S. S. P. Parkin, Appl. Phys. Lett. 78, 3103 (2001); M. F. Gillies, A. E. T. Kuiper, J. B. A. van Zon, and J. M. Sturm, ibid. 78, 3496 (2001); J. S. Moodera, L. R. Kinder, T. M. Wong, R. Meservey, Phys. Rev. Lett. 74, 3273 (1995).

${ }^{5}$ M. Covington, J. Nowak, and D. Song, Appl. Phys. Lett. 76, 3965 (2000); P. Rottländer, H. Kohlstedt, P. Grünberg, and E. Girgis, J. Appl. Phys. 87, 6067 (2000).

${ }^{6}$ H. Boeve, J. De Boeck, and G. Borghs, J. Appl. Phys. 89, 482 (2001); J. J. Sun, K. Shimazawa, N. Kasahara, K. Sato, S. Saruki, T. Kagami, O. Redon, S. Araki, H. Morita, and M. Matsuzaki, Appl. Phys. Lett. 76, 2424 (2000).

${ }^{7}$ S. Tanoue and A. Yamasaki, J. Appl. Phys. 88, 4764 (2000).

${ }^{8}$ R. S. Beech, J. Anderson, J. Daughton, B. A. Everitt, and D. Wang, IEEE Trans. Magn. 32, 4713 (1996); T. S. Plaskett, P. P. Freitas, J. J. Sun, R. C. Sousa, F. F. da Silva, T. T. P. Galvao, N. M. Pinho, S. Cardoso, M. F. da Silva, and J. C. Soares, Proceedings of the Mat. Res. Soc. Conference, Symp. M, Spring (1997).

${ }^{9}$ C. L. PLatt, B. Dieny, and A. E. Berkowitz, Appl. Phys. Lett. 69, 2291 (1996).

${ }^{10}$ T. S. Plaskett and P. P. Freitas, J. Appl. Phys. 76, 6104 (1994).

${ }^{11}$ F. Montaigne, M. Hehn, and A. Schuhl, Phys. Rev. B 64, 144402 (2001).

${ }^{12}$ C. Tiusan, M. Chshiev, A. Iovan, V. da Costa, D. Stoeffler, T. Dimopoulos, and K. Ounadjela, Appl. Phys. Lett. 79, 4231 (2001).

${ }^{13}$ T. Mitsuyu, S. Ono, and K. Wasaj, J. Appl. Phys. 51, 2464 (1980).

${ }^{14}$ R. G. Heideman, P. V. Lambeck, and J. G. E. Gardeniers, Opt. Mater. (Amsterdam, Neth.) 4, 741 (1995).

${ }^{15}$ T. K. Subramanyam, B. Srinivasulu Naidu, and S. Uthanna, Opt. Mater. (Amsterdam, Neth.) 13, 239 (1999).

${ }^{16}$ T. Dietl, H. Ohno, F. Matsukura, J. Cibert, and D. Ferrand, Science 287, 1019 (2000); J.-J. Wu, S.-C. Liu, and M.-H. Yang, Appl. Phys. Lett. 85, 1027 (2004).

${ }^{17}$ M. Hehn, O. Lenoble, D. Lacour, C. Féry, M. Piécuch, C. Tiusan, and K. Ounadjela, Phys. Rev. B 61, 11643 (2000).

${ }^{18}$ T. Lamara, M. Belmahi, O. Elmazria, L. Le Brizoual, J. Bougdira, M. Rémy, and P. Alnot, Diamond Relat. Mater. 13, 581 (2004).

${ }^{19}$ L. Smardz, U. Köbler, and W. Zinn, J. Appl. Phys. 71, 5199 (1992).

${ }^{20}$ W. F. Brinkman, R. C. Dynes, and J. M. Rowell, J. Appl. Phys. 41(5), 1915 (1970).

${ }^{21}$ J. J. Akerman, R. Escudero, C. Leighton, S. Kim, D. A. Rabson, R. W. Dave, J. M. Slaughter, and I. K. Schuller, J. Magn. Magn. Mater. 204, 86 (2002).

${ }^{22}$ Y. Xu, D. Ephron, and M. R. Beasley, Phys. Rev. B 52, 2843 (1995).

${ }^{23}$ R. Stratton, Phys. Chem. Solids 23, 1177 (1962).

${ }^{24}$ J. C. Slonczewski, Phys. Rev. B 39, 6995 (1989).

${ }^{25}$ C. L. Platt, A. S. Katz, E. P. Price, R. C. Dynes, and A. E. Berkowitz, Phys. Rev. B 61, 68 (2000).

${ }^{26}$ L. F. Lou, J. Appl. Phys. 50, 555 (1979).

${ }^{27}$ A. H. Davis and J. M. MacLaren, J. Appl. Phys. 87, 5224 (2000). 